INTERNATIONAL DESIGN CONFERENCE - DESIGN 2018

https://doi.org/10.21278/idc.2018.0175

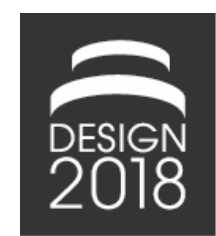

\title{
UNDERSTAND SUSTAINABLE PACKAGING DESIGN IN PRACTICE
}

\author{
X. Ma and J. Moultrie
}

\begin{abstract}
Packaging waste is known to be a significant problem for firms and society. Packaging materials constitute $65 \%$ of global solid waste. Increasingly, the cost of processing packaging waste is being directed to firms through legislation and stricter regulations. However, the sustainable packaging work in practice remains unclear and the packaging waste is still an issue. To solve this problem, seven interviews were conducted with the sustainable packaging tool users and tool providers. The interviews were transcribed and analyzed. It is clear that there are gaps between tool providers and users.
\end{abstract}

Keywords: sustainable design, packaging, design tools

\section{Introduction}

Packaging is generally not deemed useful after it has fulfilled its main purpose, which is to protect and promote the product it contains. As a result, packaging is considered to be a significant burden for the environment and a disrupting waste to consumers (Sonneveld et al., 2005). Recycling of packaging is encouraged, but consumers often find this to be very complex as a result of inconsistent rules and practices in different geographical regions. Packaging can consist of many different layers and materials, each of which needs to be dealt with in a different way. Recently, packaging sustainability has been receiving an increasing amount of attention in both academia (e.g. Byggeth and Hochschorner, 2006; Beitzen-Heineke et al., 2015) and also the popular media. Indeed, plastic packaging in particular has become a publicly and politically important topic, with companies and governments making pledges to reduce harmful plastic content, and consumers taking packaging sustainability into consideration when purchasing (Hoogland et al., 2007; Magnier and Schoormans, 2015). Due to increasing environmental consciousness, governments have launched standards and regulations to regulate green packaging.

Research into the environmental and economic impacts of packaging sustainability has, as a consequence, been stimulated by these regulations and market pressure, resulting in numerous packaging sustainability guidelines, theories, strategies and tools. These have been made available to various stakeholders, including designers, engineers, technologists, marketers and environmental managers in the production, transportation and distribution areas of packaging production.

Whilst this increasing attention is a much needed development, it is evident that the proliferation of sustainability assessment methods and regulations has not yet had a significant impact on the sustainability of packaging being produced. We may speculate on a number of reasons for this: the inherent complexity of the problem may result in designers feeling unable to make a satisfactory difference; legislation or regulation may limit the scope that designers have; designers may seek to design sustainably but may feel that decisions on packaging type are out of their field of influence; the available methods and tools may not be sufficiently clear or accessible; and diversity or inconsistency 
in language and terminology may result in tools being inaccessible (Monkhouse et al., 2004; Verghese et al., 2010; Verghese et al., 2015).

For significant improvements in packaging sustainability, it is critical to start with the design of the packaging itself. It is thus, therefore essential that we gain a better understanding of how packaging is designed in practice and the barriers to implementing sustainable design principles.

This study seeks to understand the current state of sustainable packaging design in companies through a series of seven interviews with packaging design professionals.

\section{Methodology}

We specifically set out to identify participants who are seeking to improve the sustainability of their packaging and identified these people through their cooperation with an international non-profit organisation which explicitly seeks to provide guidance or help to companies in this area. We also interviewed sustainable design specialists who had experience in developing tools or methods for use by designers. As a result, the interviewees were from organisations which were widely geographically dispersed, and we therefore adopted a telephone interview-based approach as the most appropriate method for data collection.

All interviews were semi-structured and guided using a pre-determined set of questions and were recorded with the permission of the interviewees. Interviews adopted a conversational style to let the discussion flow naturally. After the interview, the audio data was transcribed and analyzed.

A summary of the firms and interview participants is provided in Table 1. Whilst we set out to interview designers, interviewees also included other stakeholders who have significant involvement in determining the packaging for their firm's products. This included design managers, sustainability managers, technical managers, engineers and researchers. All respondents were from R\&D departments and were chosen because their job responsibilities are related to packaging sustainability decisionmaking in companies. Some interviews led to contact suggestions with other companies and these were also successfully taken up; It was considered that such companies willing to participate in this research were also companies motivated by sustainable design and which would like to make changes in the industry.

Table 1. Companies and interviewees in this study

\begin{tabular}{|l|l|c|r|}
\hline Category & Company & Sector/Product & Interviewee \\
\hline \multirow{5}{*}{ Tool Users } & Company A & Plastic packages & Design Manager (I1) \\
\cline { 2 - 4 } & Company B & Packaging & Consumer Sustainability Manager (I2) \\
\cline { 2 - 4 } & Company C & Food and beverage company & Technical Manager (I3) \\
\cline { 2 - 4 } & Company D & Consumer goods corporation & Technical Manager (I4) \\
\hline Tool Providers & Company E & Sustainable packaging tools & Director (I5) \\
\hline & Company F & Sustainable packaging guides & Lead Researcher (I6) \\
\cline { 2 - 4 } & Company G & Sustainable packaging software & Senior Engineer (I7) \\
\hline
\end{tabular}

The interview questions were based on a similar structure for all interviewees, but tailored according to their specific area of expertise. The interview consisted of 4 main sections:

1. Introduction to this research, the researcher and the research group.

2. Basic information about interviewees.

3. Exploration of sustainable packaging issues within interviewees' area of expertise.

4. Discussion of sustainable packaging issues within interviewees' area of expertise.

The questions used to guide the interview are attached in Appendix A and B. Questions were planned through a literature review and discussions with professionals in design management and sustainable manufacturing. Interviews lasted between 35 and 55 minutes.

Data was analysed using an open coding approach, with support of software 'Nvivo'. Results are presented in two sub-sections, the first focusing on responses from tool 'users' and the second from tool 'developers'. 


\section{Results}

\subsection{Results of the interviews of tool users}

\subsubsection{Company $A$}

Company $\mathrm{A}$ is a product design and engineering company that produces plastic components. It has several design centres around the world and has expertise in designing and producing plastic bottles, including: folding, moulding, thermoforming and injection moulding. The participant is the design manager in Company A. He has a team of six people who are in charge of all packaging design and development in Company A.

- People responsible for packaging design: Packaging design happens concurrently with product development. The design team-work closely with the technical and marketing team to ensure the practicality and sustainability of the packaging. They have a checklist for assessing the sustainability of packaging from the beginning to the end of the packaging life-cycle. This checklist helps the design team to consider sustainable design issues at each stage of the design process with a series of guiding questions. During the different phases of design, they also refer back to those questions to judge whether they are meeting expectations, and to evaluate any reasons for not doing so.

'We built sustainable design into the whole process from beginning. It's something we started doing very recently but we do have a checklist at several different stages in the design process.

Design process that prompts us to think of sustainable design at each stage even before we start a project.' (II)

- Tools that have been used during the packaging design and development process: With regard to sustainable packaging design, the design team do not use any specific 'tool' and instead rely mainly on personal knowledge and experience. They use some creativity tools during the brainstorming stage to help them choose and prioritise different design concepts. The interviewee also mentioned an online circular economy toolkit, which has assessment tools available and these are, at times, used to help the team prioritise and choose generic design tools.

- Difficulties encountered in using tools: The participant highlighted the potential additional costs and difficulties of realising circular designs. He felt that this could lead to a commercial disadvantage if they were undercut by competitors or if consumers did not buy in the concept of a certain design.

'By proposing designs that are circular which may be either more expensive or more difficult to do, whereas other people who don't do that and can implement cheaper products.' (I1)

- Motivations for supporting sustainable packaging design: Reducing environmental impact was the company's first concern. They recognise that some consumers want designs to be more sustainable and a few big supermarket chains are encouraging the company to have more sustainable packaging designs. However, the interviewee believes that both customers and retailers do not want to pay extra for sustainable packaging.

'I think one of the big drivers for us is because our customers are wanting us to do it. We've got quite severe push from a couple of the big supermarket chains certainly saying that if you don't design with circular economy in mind, we'll go to someone else who does. So that's quite a big driver for us.'(II)

- Difficulties encountered in designing sustainably: Increasing price to enable better sustainability was their major concern. They also noted that some technologies were not mature enough to support sustainable packaging design. For example, packaging companies have effective technologies for separating products which increase the shelf life of food, which therefore helps reduce food waste. However, these products are not necessarily easy to recycle. Another example is that plastic packs that do not have to be separated or sorted can easily be recycled. However, to ensure shelf-life of products, packaging companies have to use a combination of different plastics. 
- Suggestions for sustainable packaging design tools: For the interviewee, two types of tool require improvement: tools to support creativity tools for technical analysis of designs.

'There are the creative tools which are the brainstorming and material tracking and things like that. There are also the more technical tools like mould flow analysis, finite element analysis that we can do on computers to our products to improve them as well. So we can try to predict how products will behave before we mould them. And for those sort of tools, the technologies behind that are moving quite quickly. So there are always areas there that we can learn from to make our designs use less plastics to achieve the same physical strength or properties we are looking for.'(I1)

\subsubsection{Company $B$}

Company $\mathrm{B}$ is a provider of corrugated packaging in Europe and a specialist in plastic packaging worldwide. It operates across 36 countries and employs more than 26,000 people. The participant is a customer sustainability manager. His major responsibility is to bridge the gap between technical aspects of sustainability, regulations, and the political climate, as well as being someone who brings a marketing and commercial mind-set to try and join things together. He works closely with commercial teams, including sales, marketing, account directors, and ecommerce innovation.

- People responsible for packaging design: Company B has a large design network and a lot of designers. They work closely with psychologists and vision scientists. In the early stages of design, they consider issues such as how much material needs to be used in a new piece of packaging. The company has a mock supermarket tool called Impact Senses in which 'customers' can visit and see all the products. The impact of packaging as seen on the shelves is analysed by the company's team of psychologists, vision scientists and marketing staff. Feedback from this process might influence packaging shape and overall design.

- Tools that have been used during the packaging design and development process: The company uses an internal tool called 'the value tool'. This tool enables a qualitative estimation of environmental impact but does not offer any quantitative analysis. The company also cooperates with Fefco (the European Federation of Corrugated Board Manufacturers), who conduct an industry life cycle assessment once every three years. As part of this, Company B submits all its data to Fefco. Fefco produces a life cycle assessment for the average corrugated box, which the company uses as its reference point.

- Difficulties encountered in using tools: A significant problem is that the company cannot add any costs in order to improve packaging sustainability. If the packaging can reduce, for example, damage to a product or reduce food waste by one of two percent then the sustainability benefits and the cost savings are bigger. As a result an understanding of the relevant trade-offs is required so that people can see the bigger picture. Another issue is that secondary packaging is often neglected and is not normally considered until after all other packaging design decisions have been made. The interviewee believes that this should be given greater attention and consideration by designers. He recognised that the product contained by the packaging is not likely to change in order to fit different packaging solutions, however, the primary and secondary packaging design could be much more integrated.

'Our company invested huge amounts of money to try to understand the science of packaging better and understand it all. And some customers are so cost focused. What is the cost of a cardboard box? They obviously just want to reduce the cost. They just want to make it more sustainable by making it smaller. But they don't consider the supply chain-the whole life cycle approach-from the sustainability point of view.' (I2)

- Motivations for supporting sustainable packaging design: Those interviewed at Company B offered three chief reasons for supporting sustainable packaging design. Firstly, the company has four strategic goals and one of them is to be a leader in sustainability. Secondly, sustainable packaging is seen as a means for the company to save money and gain more profits (i.e. reduce material). Thirdly, there are legal and reputational reasons:

'There are legal reasons and reputational reasons. As an industry, I think it's an industry that has a negative reputations. So anything we can do to change that reputations is important. And then 
absolutely, it does differentiate us from our competitors. [...] Delivering smarter packaging, clever packaging, better packaging which is also more sustainable packaging.' (I2)

- Difficulties encountered in designing sustainably: Overcoming the status-quo was noted as one of the challenges in designing more sustainable packaging. Customers get used to the packaging they buy and they are reluctant to change. The participant commented that whilst on a personal level designers understand the importance of improving packaging sustainability and they generally wanted to make the right choice, on a professional level they were not always necessarily rewarded for doing so.

'I think in our industry it's the status quo. So we try to do this, we try to change things and do things differently and try to change ways of buying packaging that have been the same for probably decades. [...] I think that's a barrier: resistance to change.'(I2)

- Suggestions for sustainable packaging design tools: With regards to the design tool that was currently in use, the participant suggests the depth for data required improvement. The company has to use general information in some areas in the life cycle approach, as more specific data is either not available or the work required to get it is not be proportional to the derived benefit.

\subsubsection{Company $C$}

Company $\mathrm{C}$ is an international food and drink company. Its $\mathrm{R} \& \mathrm{D}$ centres work closely with factories in the local area and change the design of their products accordingly. To deal with packaging issues, in some projects it also hires agencies and packaging technologists. The interviewee is responsible for looking after Company C's beverage products in the UK.

- People responsible for packaging design: The work is done by Company C's R\&D centre who work with the factories and local packaging technologists.

- Tools that have been used during the packaging design and development process: EcodEX is the major tool used. It provides a numeric 'index' in order to compare different design concepts in an objective way. Sometimes the design team will conduct a full life cycle analysis with the help of independent experts.

- Difficulties encountered in using tools: EcodEX requires a variety of different inputs and reliable data is not always easy to collect. For example, changes to recycling facilities introduced by local authorities introduce data uncertainties. As a result, data such as the "percentage of recycling material' may vary and thus the analysis from EcodEX may not always be reliable. Trying to obtain this background information regarding material recyclability in different settings pose significant challenges. The whole area of recyclability is constantly changing. For instance, there are new materials being produced all the time, different suppliers make different clinch for the materials' recyclability and finally the situation is different in different countries, or even across different areas of the UK.

- Motivations for supporting sustainable packaging design: Global companies such as Company $\mathrm{C}$ are keen to demonstrate their commitment to supporting sustainable design. The reduction of waste, through sustainable design, in the whole supply chain also makes good business sense. The commitment also corresponds to an increasing demand from consumers, who are much more aware of sustainability issues than in the past.

- Difficulties encountered in designing sustainably: The biggest challenge identified was maintaining the functionality of the packaging whilst at the same time increasing its sustainability. For example, in order to make the coffee cups water-proof, the company needs to press the plastic and the paper together and as a result the packaging is difficult to recycle. In addition, sometimes it is difficult to change from one material that has been used for many years to something that is more sustainable.

- Suggestions for sustainable packaging design tools: The company would benefit from improved tools addressing both creativity and also technical sustainable design issues. The information in the sustainable packaging domain changes frequently and thus, tools which can provide readily available information and update this information frequently would make packaging design tools more desirable for the users. 
'Readily available information on how recyclable a material is in the UK, how much land is used per ton of the material, how much water is used per ton material, how much energy is used for the material, because these are all the inputs we have to put into the tool. And we just have to try to find those by asking around. Because as I said that information changes all the time.'(I3)

\subsubsection{Company D}

Company $\mathrm{D}$ is a multinational manufacturer of diverse product ranges including family, personal and household products. They have senior scientists at the company to monitor packaging. The company launches sustainability reports for the global consumers. The participant is a senior scientist at Research development in P\&G and he oversees packaging for EU regions, some of the Latin America and for British regions.

- Tools that have been used during the packaging design and development process: The company has some internal tools to help it compare different design concepts, but the participant could not give the specific name for these tools. They also use some generic Life Cycle Assessment (LCA) tools.

'We have some internal tools which we will do an assessment of a new pack that we are doing. It will compare the old versus new. We do have some internal tools and we do have some LCA tools for some of our products which we certainly do. We don't do a huge amount of them.' (I4)

- Difficulties encountered in using tools: The company did not encounter many difficulties in using tools. The company is developing tools to provide design guidance and also a scorecard method to help the designers assess the impact of designs. These tools only give directions to work further.

- Motivations for supporting sustainable packaging design: The company set very clear guidance about their sustainability claims and there are high standards which departments have to meet before they can consider externally reporting their sustainability achievements. Also, the company has targets such as reducing its amount of packaging use by twenty percent by 2020 . In addition, as an R\&D related company, being innovative is its main aim. The company tries to improve on this all the time.

- Difficulties encountered in design sustainably: Packaging design is a complex process requiring the consideration of many different factors. Understanding the whole customers' user experience of packaging presents a number of competing challenges. The packaging must: protects the product, be easily producible, be sent through supply chain, be delivered from the store to the home safely, and be either recycled, returned or used correctly afterwards. As a result, there are many competing considerations for the design team to consider to ensure sustainability from cradle to grave. The costs of ensuring sustainability are also another barrier to making improvements. The company has good intentions regarding sustainability but recognises that it is always going to be difficult. These issues have been exist within the company.

- Suggestions for sustainable packaging design tools: As the firm is a buyer and user of packaging, they are reliant on their suppliers for the sustainability of the packs. As a result, the interviewee was not sure what tools might be needed to improve this. Once the company buys a design package, it assumes that it can work well. It rarely uses any tools to compare them.

\subsection{Results of the interviews of tool providers}

\subsubsection{Company E}

Company $\mathrm{E}$ is an industry council for research on packaging and the environment. By publishing packaging reports and other packaging tools, their aim is to help manufacturers and retailers working together to promote responsible packaging for resource-efficient sustainable supply chains. It is a nonprofit organization which relies on an annual subscription from its members. The participant was the director in Company E.

- Effectiveness of the tools/advice: Owing to the prohibitive cost, Company $\mathrm{E}$ has not been able to measure the effectiveness of the tools they provided, but would ideally like to. 
'We always felt that it would be good to be able to measure its [the tool's] effectiveness. But it's an expensive thing to do. And we just try to stimulate people to use it.' (I5)

- Advantages of the tools/advice: Company E operates around the supply chain. They provide data from hard research like life cycle assessment and soft research such as consumer opinions. Tools developed by Company E examine the environmental and social impact of packaging. No commercial impact is considered. In this sense the Company $\mathrm{E}$ is a more impartial industry body.

- Limitations of the tools/advice: The biggest limitation was getting good numerical data. The available data was generic.

'We are guessing how much packaging there is on the market. The packaging is incidental to the product. Products are well measured. You know how many tons of peaches are coming to the country but you don't know how they are packaged because it's not be of interest to people at all.' (I5)

- Companies using tools/advice: Companies using the tools mainly produce consumer goods. However, they all seek to be leaders in sustainability and want to make changes to society.

- Differences in the advice/support needed in different types of firm: The general principles are similar for different types of firms as the guidance provided by Company E is simplistic. With regards to food packaging, which forms over two thirds of sales packaging, there are safety issues to consider. Electronic packaging is more sophisticated.

'The general principles are the similar because really it's a very simplistic guidance. Asking themselves sensible questions: how is this going to be used, how is this disposed of, how many resources going and those general principles apply to any sort of product and any sort of packaging.' (I5)

\subsubsection{Company $F$}

Company $\mathrm{F}$ is a global non-profit organization working to transform the consumer goods industry by partnering with leading companies to define, develop, and deliver more sustainable products. The participant is the lead researcher on packaging in Company $\mathrm{F}$.

- Effectiveness of the tools/advice: Tool users seem only to need generic information. Tools developed by Company $\mathrm{F}$ help users ask questions about how much of the packaging content they are designing/using can be recycled and how much is renewably sourced. This information satisfies most of their clients' needs.

'From the retailers' perspective, they need to censor their actions in other information as well, such as greenhouse gas emissions, water use, worker health and safety. The packaging questions are something important but it's just a few questions and our overall survey will satisfy retailer's needs.' (I6)

- Advantages of the tools/advice: Company F acts as a centre of information, helping users make more informed choices.

'In terms of comparing what the sustainability consortium offers versus another tool, the consortium more serves as a central place for information and then a retailer can use that information to determine what suppliers are doing better on which aspects of sustainability and then the guidance section is where references those other tools.' (I6)

- Limitations of the tools/advice: Obtaining the data from the users and improving the data base of the tools was the biggest issue that Company F encountered.

'So the main challenge is that the transparency in the supply chain specifically with the packaging suppliers and getting the better understand that an important question of quality verses reduction and materials and what types of content do using.' (I6)

- Companies using tools/advice: The main companies using Company F's tools are retailers, such as Walmart, their principal user, Amazon, Marks and Spencer and a number of other European retailers.

- Differences in the advice/support needed in different types of firm: Tools in Company $F$ related to the recyclable content. In different industries the percentage of recyclable content varies 
a lot. However, this kind of difference did not influence the advice Company F provided for different companies. In the end the participant mentioned one important element he considered to be important in sustainable packaging research; namely education. Therefore, he thinks including education and how to recycle labels on products is also very important.

'The only other theme that I want to make sure that cover our conversation was another proponent of what these companies and retailers are advocating for is the educational component. Especially on the consumer's standpoint there's a lot that can be done from the packaging design component but if consumers are fully able to understand how to actually recycle the product itself or study recycling programs don't support the different numbers on the different recycled materials then that's another hurdle the jump over.'(I6)

\subsubsection{Company $G$}

Company G produces a streamlined Life Cycle Assessment (LCA) tool designed to assess the environmental impacts and resource consumption profiles of different packaging options. It is designed to be intuitive and easy to use. Company $\mathrm{G}$ allows a complete assessment to be undertaken in less than 30 minutes. The participant is the senior engineer in Company G.

- Effectiveness of the tools/advice: In most cases, Company $G$ helps designers and managers to assess their preliminary design concepts. Also, Company G can be used for major changes to the packaging. The idea of the tool is help users to think back to the design departments.

- Advantages of the tools/advice: The main advantage is that prior knowledge is not needed to use the tool. It is designed to be as simple as possible to use. The tool also includes different packaging types such as primary packaging, secondary packaging and tertiary packaging, as well as logistics. The designers and engineers of Company $\mathrm{G}$ took packaging technologists' behaviour into consideration while designing the tool.

'So the language and structure of the tool oriented to be in the way we think packaging design as a technologist think, behave, and model so it's the oriented to the language and structure of their thinking.' (I7)

- Limitations of the tools/advice: This tool is suitable for business to business communication but not business to consumer. Additionally, it provides generic data so an assessment can be done very quickly but the data it provides is not complete.

'We can get $80 \%$ of the results for $20 \%$ of the effort. We typically say that it's half an hour to sixty minutes to model your LCA. A real LCA takes weeks or months, hundreds of thousands of dollars. So we can get the juicy bit. The $80 \%$ for $20 \%$ of the effort but you're always missing that twenty percent.' (I7)

- Companies using tools/advice: The tool users covered the whole supply chain in different industries. Core users were not only food and beverage companies but also spanned cosmetics, mobile phones, sports apparel and shoes and pharmaceutical companies.

'It's broken up into material suppliers, packaging companies and food, beverage, product manufacturers as well as people in the cosmetics area. We had L'Oréal, Estée Lauder. We have a couple in the pharmaceutical area: Bristol-Myers Squibb devices. We have some and then quite a lot in food and beverage.'(I7)

- Differences in the advice/support needed in different types of firm: The interviewee recognised that different types of company will have different drivers but was unsure as to whether this was reflected in the advice Company G provided.

'Companies have different drivers. So for L'Oréal you know there is a very strong internal driver. Their customers expect them to be the best and assume that they do good things for the environment. For them it's very much about they view themselves. So their driver is very internal. Maybe for food and beverage sometimes it's more of local regulations and pressure on food and beverage companies. People focus on waste recycling purpose item, used bottles of water bottles and coffee cups have a very high, the public has very high perceptions about things as being problematic so they, they're driven more by some of those regulatory pressures or customer pressures.' (I7) 


\section{Discussion}

This study introduced seven interviews conducted to improve understanding around the tools used in packaging design to enable sustainability. The purpose of this study is to understand what tools practitioners are using in industry, whether they are useful and how they can be improved. Four interviews were conducted with tool users and three interviews were conducted with tool providers.

\subsection{Tool users}

\subsubsection{Sustainable innovation in product development process}

In the product development process, companies are shown to be using sustainable design tools that provide general information; including checklists and guidelines. The tools mentioned the most are tools used early in the design process to support creativity and brainstorming, to enable 'sustainable innovation'. Charter and Clark (2007) defined sustainable innovation as: 'A process where sustainability considerations (environmental, social, financial) are integrated into company systems from idea generation through to research and development (R\&D) and commercialization. This applies to products, services and technologies, as well as new business and organization models.' Compared to ecoinnovation, sustainable innovation not only addresses environmental and economic dimensions but also the boarder social and ethical dimensions (Charter and Clark, 2007). Interviewed companies use sustainable innovation methods in their product development process. They care about the social impact of their products in sustainability as well as their positive sustainable image in public. They actively seek to use innovative tools at the beginning of product development stage to ensure their products can convey this message to society.

\subsubsection{Difficulties of designing sustainably}

Company A and Company $\mathrm{C}$ believed that current technology was not mature enough for packaging to be designed sustainably and at the same time adequately fulfill function requirements (e.g. protecting the product). Company B thought consumer behaviour was to be the biggest barrier to changing packaging design. Company D identified complexity resulting from the numerous factors that contribute to a package's life cycle as a key challenge to creating sustainable designs. These difficulties may be explained by the fact that packaging often has a longer lifecycle than the product it contains (Svanes et al., 2010; Wever, 2012), especially in the FMCG sector, with products such as shampoo, food and beverages. Once the product no longer requires packaging, the packaging has to go through the disposal and recycle phase, the success of which are highly related to the design of packaging. This includes the choice of the materials, the structure of the materials in packaging, the shape of the packaging, and the mark on the packaging which leads consumers to recycle it in the right way. Interviewees noted that it is hard to consider the whole picture during the design process.

Another major concern is the perceived cost of making packaging more sustainable. Half of the interviewed companies expressed their concern regarding the addition of extra cost if they implement solutions based on analysis from sustainable packaging tools. In addition, they perceived significant time and therefore cost in using the tools. The cost of using and applying these tools is thus one of the main barriers to their adoption.

This perceived cost of more sustainable packaging is counter to the views of Azzi et al. (2012), who state that the cost of materials as well as costs related to manufacturing processes, logistic processes, supply chain relationships, environmental costs and other hidden costs will be reduced if companies design packaging sustainably. Thus, education regarding sustainable packaging should be given not only to consumers, but also the designers and managers. If we want to motivate companies to adopt sustainable packaging design, they need to understand the benefits they can get from doing it. This is interesting and worthy of further study.

\subsubsection{Motivation of designing sustainably}

All companies noted that their motivation for designing sustainability stemmed from commitments they had previously made for environmental and societal reasons. To promote a positive image among the 
public it is important for companies to write the sustainability aim in their companies' goals or guidance. Whilst recognising this motivation, this is often translated into designs which make small incremental improvements but which are still not sufficiently environmentally benign.

\subsection{Tool providers}

\subsubsection{Advantages of developed tools}

The report developed by Company E examines the whole supply chain and provides a generic picture to the users. It is developed by an NGO and does not look into the commercial side of packaging sustainability. It is, therefore, more impartial than other tools. Company F offered a great source of information to retailers and helped them to decide which suppliers to choose. As a packaging sustainable design software, Company $\mathrm{G}$ provided a user-friendly operation process and operation language.

None of these tools, however, considers the interaction between the product and the packaging system. This is especially important for food and beverage packaging. When the product inside gets damaged, it will have a greater environmental impacts and cost than the packaging itself (Jungbluth et al., 2000; Williams et al., 2008; Roy et al., 2009). In this instance, the environmental impact and cost of a damaged product would be greater than that saved by having more sustainable packaging.

\subsubsection{Difference of developed tools for different companies}

Company $\mathrm{E}$ and Company $\mathrm{G}$ provided similar advice for their users regardless of their packaging output. Tool providers understood that the drivers of different companies using their tools may vary but the general information they needed to improve their sustainable packaging design will not change much. This may be related to the generic information the tools provide. Tools from Company E provide some self-check questions for designers and managers to ask themselves during research and development process. Company $\mathrm{G}$ provides general waste data of designed packaging in each phase along the supply chain. Thus, we can observe that the output of each design tool might need to be more nuanced, and should better reflect the nature of the product which is being packaged. For example, food packaging needs the packaging to protect the quality of its content and electric products need the packaging to protect its fragile components from pressure.

\subsection{Data reliability and precision}

A key issue, raised by both tool developers and users is the need for data underpinning design tools which is both reliable and up to date. It is evident that small changes in the supply, consumption or recycling systems can have a significant impact on the environmental performance of different types of packaging. This is an especially difficult challenge, as the designer often has little influence over these changes in downstream systems.

\section{Conclusion}

This paper presented and analysed a set of interviews with sustainable packaging tool users and tool providers. Surprisingly, it is not common for companies designing packaging to use the tools specifically created to improve sustainability of packaging design. The tools being used provided generic information for the users. The main reason that most users did not use sustainable packaging design tools is the perception that this would add extra cost and they believed that their consumers would not pay for it. The biggest driver for the users to design packaging sustainably was having a positive image among the public and protecting the environment. However, the cost and the immature packaging technology may make it hard to realize sustainable packaging design and development.

It was also evident that whilst providing benefits to their clients, the tool developers were not systematically evaluating the usefulness of their developed tools. Tool providers considered it to be very challenging to obtain more accurate data and create a relatively complete database. Different users in different industries received similar advice from tool providers. Although their focuses are slightly different, the advice provided was general and almost applicable for all sectors. 
After the analysis of the interview, some of the reasons for the underperformance of current tools are emerging. Cost is perceived to be the major barrier to applying sustainable packaging design in product development and the design process. Also related to the cost is the difficulty of obtaining useful and readily available packaging data from the current tools. Tools and methods used in companies vary but the ones used tend to be 'generic' and as a result only provide generic packaging information or suggestions. Because of their generic characteristic they can be applied across different industries. But, to make the tools more effective, tool providers might consider greater 'tailoring' of the tools for use in specific sectors or for specific types of packaging.

Reliability and availability of data to enable meaningful analysis is a critical issue for the whole packaging industry. It is not possible for this to be done by a single organisation and thus, there is a need for greater collaboration across the whole packaging industry to make this happen.

\section{References}

Azzi, A., Battini, D., Persona, A. and Sgarbossa, F. (2012), "Packaging design: general framework and research agenda”, Packaging Technology and Science, Vol. 25 No. 8, pp. 435-456. https://doi.org/10.1002/pts.993

Beitzen-Heineke, E.F., Balta-Ozkan, N. and Reefke, H. (2015), "The prospects of zero-packaging grocery stores to improve the social and environmental impacts of the food supply chain", Journal of Cleaner Production, Vol. 140 No. 3, pp. 1528-1541. https://doi.org/10.1016/j.jclepro.2016.09.227

Byggeth, S. and Hochschorner, E. (2006), "Handling trade-offs in Ecodesign tools for sustainable product development and procurement", Journal of Cleaner Production, Vol. 14 No. 15-16, pp. 1420-1430. https://doi.org/10.1016/j.jclepro.2005.03.024

Charter, M. and Clark, T. (2007), Sustainable innovation: Key conclusions from sustainable innovation conferences 2003-2006 organised by The Centre for Sustainable Design, The Centre for Sustainable Design, Farnham, UK.

Hoogland, C.T., de Boer, J. and Boersema, J.J. (2007), "Food and sustainability: do consumers recognize, understand and value on-package information on production standards?", Appetite, Vol. 49 No. 1, pp. 47-57. https://doi.org/10.1016/j.appet.2006.11.009

Jungbluth, N., Tietje, O. and Scholz, R.W. (2000), “Food purchases: impacts from the consumers' point of view investigated with a modular LCA”, The International Journal of Life Cycle Assessment, Vol. 5 No. 3, pp. 134142. https://doi.org/10.1007/BF02978609

Magnier, L. and Schoormans, J. (2015), “Consumer reactions to sustainable packaging: The interplay of visual appearance, verbal claim and environmental concern”, Journal of Environmental Psychology, Vol. 44, pp. 5362. https://doi.org/10.1016/j.jenvp.2015.09.005

Monkhouse, C., Bowyer, C. and Farmer, A. (2004), Packaging for Sustainability: Packaging in the Context of The Product, Supply Chain and Consumer Needs, Institute for European Environmental Policy (IEEP), London.

Roy, P., Nei, D., Orikasa, T., Xu, Q., Okadome, H. et al. (2009), “A review of life cycle assessment (LCA) on some food products”, Journal of Food Engineering, Vol. $90 \quad$ No. 1, pp. 1-10. https://doi.org/10.1016/j.jfoodeng.2008.06.016

Sonneveld, K., James, K., Fitzpatrick, L. and Lewis, H. (2005), "Sustainable packaging: how do we define and measure it", Proceedings of the 22nd IAPRI Symposium on Packaging, Campinas, Brazil, May 22-24, 2005, International association of packaging research institutes (iapri).

Svanes, E., Vold, M., Møller, H., Pettersen, M.K., Larsen, H. and Hanssen, O.J. (2010), "Sustainable packaging design: a holistic methodology for packaging design", Packaging Technology and Science, Vol. 23 No. 3, pp. 161-175. https://doi.org/10.1002/pts.887

Verghese, K., Horne, R. and Carre, A. (2010), "PIQET: the design and development of an online 'streamlined'LCA tool for sustainable packaging design decision support", The International Journal of Life Cycle Assessment, Vol. 15 No. 6, pp. 608-620. https://doi.org/10.1007/s11367-010-0193-2

Verghese, K., Lewis, H., Lockrey, S. and Williams, H. (2015), "Packaging's role in minimizing food loss and waste across the supply chain", Packaging Technology and Science, Vol. 28 No. 7, pp. 603-620. https://doi.org/10.1002/pts. 2127

Wever, R. (2012), "Design research for sustainable behaviour”, Journal of Design Research, Vol. 10 No. 1-2, pp. $1-6$.

Williams, H., Wikstrom, F. and Lofgren, M. (2008), "A life cycle perspective on environmental effects on customer focused packaging development", Journal of Cleaner Production, Vol. 16 No. 7, pp. 853-859. https://doi.org/10.1016/j.jclepro.2007.05.006 


\section{Appendix A: Interview protocol for tool users}

Date: Name of the company:

Questions:

- Would you mind if I recorded this conversation so I don't miss any details?

- Would you prefer to keep our conversation anonymous?

- Could you please briefly introduce yourself?

- Who is responsible for packaging design? Are they part of the product design team?

- At what stage of the development process are you using sustainable tools for packaging design? Does it happen concurrently with product development, or does it happen after product development?

- What tools do you use to support sustainable packaging design?

- Have you encountered any difficulties in using these tools?

- Why are you using tools to support sustainable packaging design?

- What are the barriers to designing more sustainable packaging?

- How difficult is it to implement new packaging ideas in production?

- What are the advantages of designing more sustainable packaging?

- How might these tools be improved?

\section{Appendix B: Interview protocol for tool providers}

Date: Name of the company:

Questions:

- Would you mind if I recorded this conversation so I don't miss any details.

- How do designers use the tools or advice that you produce?

- What are the advantages of the tools/advice that you produce in comparison with other tools?

- What are the limitations in the tools/advice that you currently offer?

- What kind of companies use your tools/advice?

- I am interested specifically in firms producing products, not FMCG (e.g. bottles, food packaging). Is there a difference in the advice/support needed in different types of firm?

- Do you have any case examples of packaging in this sector which is excellent from a sustainability perspective?

- Can you put me in touch with any firms who you know are doing a good job?

Xuezi Ma

University of Cambridge, Department of Engineering

17 Charles Babbage Rd, CB3 0FS Cambridge, United Kingdom

Email: xm241@cam.ac.uk 